\title{
Evaluation of depression and anxiety symptoms, alcohol consumption, and binge eating in older adults undergoing bariatric surgery: a 6-year follow-up Avaliação dos sintomas de depressão e ansiedade, consumo de álcool e compulsão alimentar em idosos submetidos à cirurgia bariátrica: seguimento de 6 anos
}

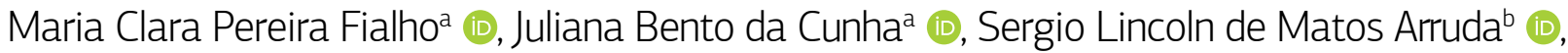 \\ Otavio Toledo Nobrega ${ }^{a}$ (1), Einstein Francisco Camargos ${ }^{a}$ (1)
}

INTRODUCTION: The literature remains scarce on the late effects of bariatric surgery on the general health of patients who underwent such procedures at an older age. The present study aimed to evaluate depression and anxiety symptoms, risky alcohol consumption, and binge eating in older adults undergoing bariatric surgery. METHODS: This study used current data (from medical records and tests) to conduct a cross-sectional study. A total of 74 individuals aged 60 years and older who underwent bariatric surgery after 55 years of age at a specialist center for obesity management located in Brazil were included and evaluated by the Beck Depression Inventory, Beck Anxiety Inventory, Alcohol Use Disorders Identification Test, and Binge Eating Scale. Demographic and clinical data related to the surgical procedure (weight loss) were also collected. The Cochran-Armitage trend test, Pearson's $\chi^{2}$ test, and a multiple linear regression model were used as needed. A p < 0.05 was considered significant. RESULTS: The individuals were white (65.70\%) and women (78.30\%), with a mean age of 65.8 (SD 3.90) years. The mean time elapsed from surgery to evaluation was 75.70 (SD 43.70) months; $10.80 \%$ of the participants had moderate to severe depression, $8.10 \%$ moderate to severe anxiety, and $5.40 \%$ risky or high-risk alcohol consumption. None of the participants had binge eating problems. Weight regain was not associated with depressive symptom severity or risky alcohol consumption, but it was significantly associated $(p=0.034)$ with few or neither anxiety symptoms. Excess weight loss was not associated with any study variable. CONCLUSION: The results show a low prevalence of mental symptoms in older adults undergoing bariatric surgery compared to data from the literature on younger adults undergoing the same procedure.

KEYWORDS: bariatric surgery; aged; depression; anxiety; alcohol drinking; binge eating; binge-eating disorder; mental health; obesity.

aniversidade de Brasília - Brasília (DF), Brasil.

'Hospital Regional da Asa Norte - Brasília (DF), Brasil.

Correspondence data

Einstein Francisco Camargos - Setor Campus Universitário Darcy Ribeiro, s/n - Universidade de Brasília - Asa Norte - CEP: $70910-900$ - Brasília (DF), Brazil. E-mail: einsteinfc@gmail.com

Received on: 05/15/2021. Accepted on: 07/22/2021

How to cite this article: Fialho MCP, Cunha JB, Arruda SLM, Nobrega OT, Camargos EF. Evaluation of depression and anxiety symptoms, alcohol consumption, and binge eating in older adults undergoing bariatric surgery: a 6-year follow-up. Geriatr Gerontol Aging. 2021;15:e0210033. https://doi.org/10.53886/gga.e0210033

https://doi.org/10.53886/gga.e0210033 


\begin{abstract}
INTRODUÇÃO: A literatura ainda é escassa sobre os efeitos tardios na saúde geral de pacientes idosos submetidos à cirurgia bariátrica. O presente estudo teve como objetivo avaliar os sintomas de depressão e ansiedade, consumo de álcool de risco e compulsão alimentar em idosos submetidos à cirurgia bariátrica. METODOLOGIA: Este estudo utilizou dados atuais (de prontuários e exames) para realizar um estudo transversal. Um total de 74 indivíduos com 60 anos ou mais que se submeteram à cirurgia bariátrica após os 55 anos em um centro especializado em tratamento da obesidade localizado no Brasil foram incluídos e avaliados pelo Inventário de Depressão e Ansiedade de Beck, Alcohol Use Disorders Identification e Escala de compulsão alimentar. Dados demográficos e clínicos relacionados ao procedimento cirúrgico (perda de peso) também foram coletados. O teste de tendência Cochran-Armitage, o teste do $\chi^{2}$ de Pearson e um modelo de regressão linear múltipla foram usados conforme necessidade. Um $p<0,05$ foi considerado significativo. RESULTADOS: Os indivíduos em sua maioria eram brancos (65,70\%) e mulheres (78,30\%), com média de idade de 65,8 (DP 3,90) anos. 0 tempo médio decorrido desde a cirurgia até a avaliação foi de 75,70 (DP 43,70) meses; 10,80\% dos participantes tinham depressão moderada a grave, $8,10 \%$ ansiedade moderada a grave e 5,40\% consumo de álcool de risco ou alto risco. Nenhum dos participantes teve problemas de compulsão alimentar. $\mathrm{O}$ ganho de peso não foi associado à gravidade dos sintomas depressivos ou consumo de álcool de risco, mas foi significativamente associado $(p=0,034)$ com poucos ou nenhum sintoma de ansiedade. A perda de excesso de peso não se associou a nenhuma variável do estudo. CONCLUSÕES: Os resultados mostram baixa prevalência de sintomas mentais em idosos submetidos à cirurgia bariátrica em comparação com dados da literatura em adultos jovens submetidos ao mesmo procedimento.
\end{abstract}

PALAVRAS-CHAVE: cirurgia bariátrica; idoso; depressão; ansiedade; consumo de bebidas alcoólicas; bulimia; transtorno da compulsão alimentar; saúde mental; obesidade.

\section{INTRODUCTION}

Bariatric surgery is often indicated for individuals with a diagnosis of morbid obesity who may have their quality of life and life expectancy reduced as a result of this condition. According to the World Health Organization, by the year 2020, two-thirds of the diseases will be attributable to non-communicable diseases, many of them associated with high energy intake and consequent increase in chronic diseases, including obesity. ${ }^{1}$ Not rarely, these patients have a history of failed treatment of obesity and, through surgery, aim to obtain a consistent weight loss in order to improve their quality of life.

Bariatric procedures have been the most effective treatment for morbid obesity in all age groups and are considered superior to outpatient medical treatment in terms of weight loss and improvement in comorbidities and quality of life. ${ }^{2}$ An increasing number of older adults are seeking surgical intervention as a result of the demographic growth in this age group, positive social perceptions of aging, and technological advances that have significantly reduced surgical complications. Currently, one in every three older persons is obese, and the prevalence of obesity in this segment of the population is expected to increase in the coming years. ${ }^{3}$

Researchers argue that, although older adults do not benefit as much as younger adults from a bariatric procedure, the intervention is sufficiently safe and effective in the geriatric age group and has been shown to be more effective in the treatment of morbid obesity than any other medical treatment. ${ }^{2}$

Extreme obesity is also associated with significant psychiatric comorbidities, including depression, anxiety, and substance abuse disorders, most commonly risky alcohol consumption. ${ }^{4}$ According to Yen et al. approximately $40.0 \%$ of all patients undergoing bariatric surgery have at least one psychiatric diagnosis, with depression, anxiety, and binge-eating disorder as the most prevalent psychiatric diagnoses in bariatric surgery candidates. ${ }^{5}$

It should be noted that most studies of older adults undergoing bariatric surgery evaluate factors related to post-procedure morbidity and mortality, percentage of weight loss, and improvement in metabolic parameters. ${ }^{6,7}$ However, almost all studies have a follow-up of less than three years and none of them have assessed depression and anxiety symptoms, risky alcohol consumption, and binge eating or have considered elements of mental health in the postoperative period of bariatric surgery. ${ }^{8}$ In younger people, improvements in these disorders after the procedure are controversial, mainly regarding the associations between psychiatric comorbidities and weight loss after bariatric surgery. ${ }^{7-10}$ For instance, anxiety, a critical factor for obese patients, does not appear to be significantly affected after bariatric surgery in younger adults. ${ }^{11}$ However, if present after surgery, it seems to negatively influence weight loss postoperatively. ${ }^{8,12-14}$ To our knowledge, no study has evaluated these psychological factors in older adults undergoing bariatric surgery.

Ertelt et al., investigating self-reported alcohol abuse and dependence in 70 patients (mean age, 49.9 years) after Roux-en-Y gastric bypass surgery, identified that $83.0 \%$ of respondents consumed alcohol, and of these, $84.0 \%$ reported an increased sensitivity to the effects of alcohol after surgery. ${ }^{15}$ A Swedish study followed for up to 22 years obese non-older adults undergoing Roux-en-Y gastric bypass and found an increased risk of risky alcohol consumption and alcohol-related problems after the procedure. ${ }^{16}$ In contrast, another study identified a reduction 
in alcohol consumption from $74.0-44.0 \%$ in 19 patients after bariatric surgery. ${ }^{17} \mathrm{~A}$ study using the Alcohol Use Disorders Identification Test (AUDIT) in a sample of 1945 patients, with a mean age of 47 years, found no significant difference in risky alcohol consumption before and at one year following surgery, but an increased alcohol consumption was observed two years postoperatively. ${ }^{18}$ Despite the conflicting results, these studies point to a still high prevalence of alcohol-related problems in patients undergoing bariatric surgery. Independent variables associated with an increased likelihood of risky alcohol consumption after surgery includes male sex, younger age, and regular alcohol consumption before surgery. ${ }^{6,7,11,19}$

The aim of the present study was to evaluate the prevalence of depression and anxiety symptoms, risky alcohol consumption, and binge eating in older adults undergoing bariatric surgery.

\section{METHODS}

This observational, analytical, cross-sectional study of older adults undergoing bariatric surgery was conducted at a specialist center for obesity (private) management located in Brasilia, Federal District, Brazil. The sample consisted of 74 individuals aged 60 years and older who underwent bariatric surgery after 55 years of age $(78.30 \%$ female; mean age $65.80 \mathrm{SD}, 3.90$ years). Of note, age 60 years and above is the age range defined as older adults in Brazil. ${ }^{20}$ Patients were included if they

1. underwent the same surgical technique (Roux-en-Y gastric bypass),

2. were operated on from 2010 onward and had their data available electronically,

3. were operated on by the same surgeon and seen by a dietitian and a psychologist preoperatively and postoperatively,

4. were 55 years or older at the time of surgery, and

5. were 60 years or older at the time of recruitment for this study.

\section{Assessments}

Each participant was evaluated by a geriatrician and a psychologist during a clinical interview in which the following sociodemographic and clinical data were collected: sex, age (in completed years), marital status (married, widowed, single, divorced, or other), total schooling (years of schooling completed), length of time since surgery (in months), height $(\mathrm{m})$, body weight before surgery (as recorded in the patient's medical record), lowest weight after surgery $(\mathrm{kg})$, current body weight $(\mathrm{kg})$, and excess weight (difference between preoperative weight and ideal weight based on a body mass index (BMI) of $25 \mathrm{~kg} / \mathrm{m}^{2}$ ). Anthropometric measurements were used to determine BMI $\left(\mathrm{kg} / \mathrm{m}^{2}\right)$ and percent weight loss after surgery $(\% \mathrm{WL}=\{[$ previous weight - current weight $] /[$ previous weight] x 100\}), percent excess weight loss (\%EWL $=\{[$ previous weight - current weight $] /$ [excess weight] $\times 100\})$, and weight regain after surgery (current weight - lowest weight).

Inventories and scales validated for use in Brazil were applied by the same psychologist for variables related to anxiety, depression, risky alcohol consumption, and binge eating. The Beck Depression Inventory (BDI) was used to measure the severity of depressive symptoms. The BDI version used in this study contains 21 items relating to symptoms of depression, such as hopelessness, irritability, guilt, and feelings of being punished, as well as to physical symptoms, such as fatigue, weight loss, and lack of interest in sex. Scores of $0-11$ are classified as minimal depression, $12-19$ as mild, $20-30$ as moderate, and $31-63$ as severe depression. ${ }^{21,22}$ The Beck Anxiety Inventory (BAI) is a 21 -item scale that measures the severity of anxiety symptoms in the past week, and scores of $0-10$ are classified as minimal anxiety, $11-19$ as mild, $20-35$ as moderate, and $36-63$ as severe anxiety. ${ }^{21}$ The 10 -item AUDIT was used to assess risky alcohol consumption and drinking behaviors, and scores of $0-7$ indicate low-risk consumption or abstinence, $8-15$ indicate risky consumption, 16 - 19 indicate hazardous or harmful alcohol consumption, and $20-40$ indicate probable alcohol dependence. ${ }^{23}$ The Binge Eating Scale (BES), ${ }^{24}$ adapted to Brazil, was used to categorize eating behaviors as no binge eating ( $\leq 17$ points), moderate binge eating ( $18-26$ points), and severe binge eating ( $\geq 27$ points). ${ }^{25}$

\section{Statistical analysis}

The Cochran-Armitage trend test or Pearson's $\chi^{2}$ test were used to assess the associations of clinical variables with depressive symptoms, anxiety symptoms, binge eating, and risky alcohol consumption. A multiple linear regression model was used to assess the relationship between demographic variables and EWL\%. Pearson's linear correlation coefficient was calculated to assess the correlation of time since surgery with depressive symptoms, anxiety symptoms, binge eating, and risky alcohol consumption. Data were analyzed using SAS, version 9.4. A p $<0.05$ was considered significant.

The study was approved by the Research Ethics Committee of the School of Medicine of the University of Brasilia (protocol $n^{\circ}$. 2.761.922.3), and written informed consent was obtained from each study participant. 


\section{RESULTS}

A total of 124 patients were eligible for inclusion. After attempted telephone and/or email contact, 74 patients consented to participate in the study. Most participants were women $(n=58,78.30 \%)$, with a mean age of 65.8 (SD 3.90) years and a mean of 13.2 (SD 4.20) years of schooling. Race was self-reported as white by $65.7 \%(n=48)$ of the participants. The mean time elapsed from surgery to evaluation was 75.7 (SD 43.70) months.

Of the 74 participants, $10.80 \%(\mathrm{n}=8)$ had moderate to severe depression, $8.10 \%(\mathrm{n}=6)$ had moderate to severe anxiety, and $5.40 \%(\mathrm{n}=4)$ had a risky or high-risk alcohol consumption. None of the participants had binge eating problems. Overall, $73.00 \%(n=54)$ had never received psychopharmacologic treatment, whereas $13.50 \%(n=10)$ were receiving psychiatric treatment at the time of the study. Only $16.20 \%(\mathrm{n}=12)$ of the participants were in psychotherapy at the time of the study, whereas $39.20 \%$ (n = 29) reported never having undergone any psychotherapeutic intervention.

Weight regain was not associated with depressive symptom severity, psychiatric/psychological follow-up, or risky alcohol consumption. However, weight regain was significantly associated with few or neither anxiety symptoms $(\mathrm{p}=$ 0.034). Excess weight loss was not associated with any study variable (Table 1).

The length of time since surgery was not significantly correlated with anxiety symptoms (BAI) $(\mathrm{p}=0.538)$, depressive symptoms $(B D I)(p=0.498)$, or risky alcohol consumption $($ AUDIT) $(\mathrm{p}=0.907)$.

\section{DISCUSSION}

This study of 74 older adults undergoing Roux-en-Y gastric bypass showed that, at a mean of 6 years after the procedure, most older adults had few depressive symptoms (minimal or mild) (89.20\%), few anxiety symptoms (minimal or mild) (92.90\%), and no risky alcohol consumption (93.20\%). None of them showed the presence of binge eating behavior indicative of an eating disorder. There are no studies that have evaluated psychological disorders in older adults after about six years of bariatric surgery. In addition, the few studies that have evaluated these variables were performed in a younger population, since bariatric surgery in older people is a relatively recent procedure.

Preoperative psychological disorders are often reported in studies of younger adults undergoing bariatric surgery, especially Axis I disorders (such as depression, anxiety, eating and substance use disorders), and somehow they seem to lead to worse results in postoperative weight loss. ${ }^{8}$ Conversely, it appears that such psychiatric disorders tend to improve after surgery. A prospective Swedish study of non-older adults (mean age, 48 years) reported a significant reduction in the frequency of depression and anxiety symptoms one year after surgery, and this improvement remained until four years postoperatively. ${ }^{4,26}$ In the same vein, a study of Hispanic Americans (44.5 years) found a significant improvement in depressed mood. ${ }^{27}$ The improvement in depressive symptoms appears to occur 24-36 months after surgery. ${ }^{10}$ Unfortunately, in the present study, these symptoms were not measured preoperatively, thus precluding inferences about a change of status in our patients. Another factor that may have interfered with

Table 1. Beck depression inventory, Beck anxiety inventory, and alcohol use disorders identification test results associated with excess weight loss and weight regain.

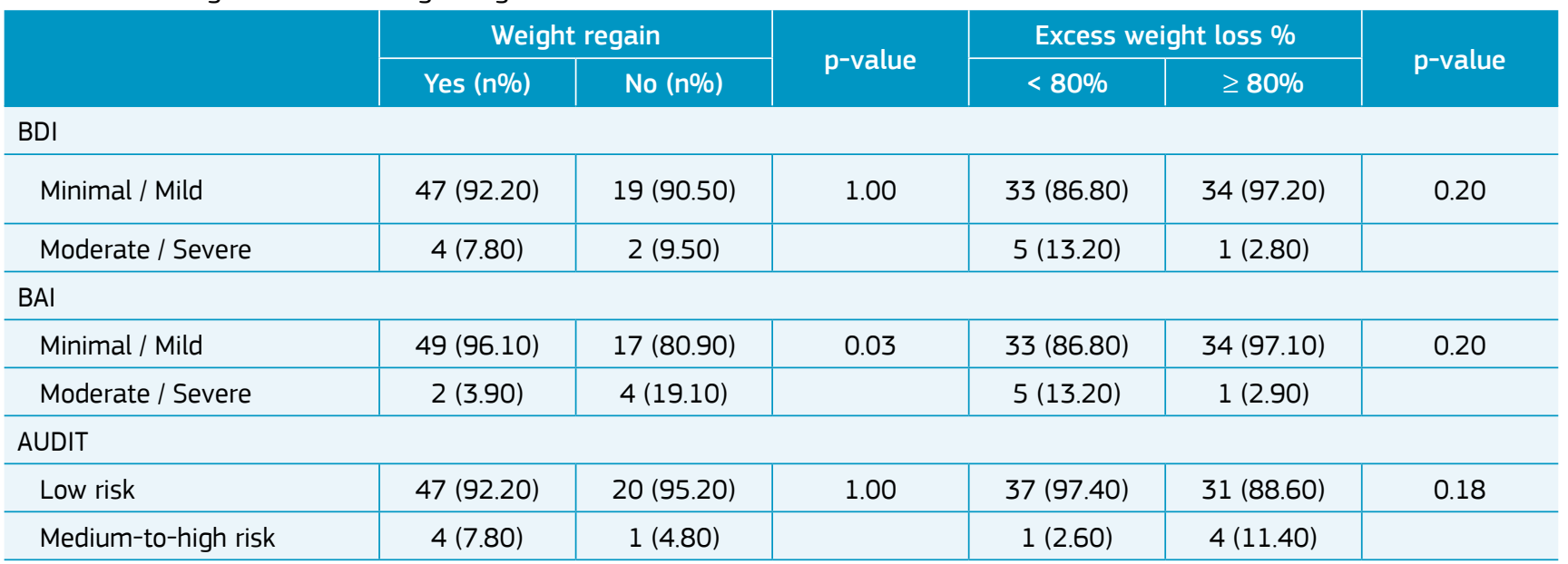

BDI: Beck depression inventory; BAl: Beck anxiety inventory; AUDIT: Alcohol use disorders identification test; $p$-value: Pearson's linear correlation coefficient. 
this variable is the rate of patients with minimal depressive symptoms using antidepressants, which was $14.80 \%$.

Henrickson et al. suggest that older bariatric patients may reframe life positively by believing that, in the past, obesity has prevented them from achieving other important milestones in their life, by hindering social relationships, employment, and many other significant milestones that provide people with a sense of well-being and adjustment. ${ }^{28}$ In both younger and older adults, weight loss through bariatric surgery may represent a chance for new situations that they have not experienced before surgery because of issues related to personal beliefs, self-image, self-esteem, or physical limitations, thus showing greater adherence to care and greater supported self-care.

Only 7.00\% of the older adults in our sample had clinically significant anxiety symptoms after bariatric surgery. However, it was precisely the majority of patients with minimal to mild anxiety symptoms that had the greatest weight regain $(p=0.034)$. This was an unexpected finding for us. However, the literature remains controversial regarding this association in non-older people. Unlike our study, Kalarchian et al. (2008) showed that patients with Axis I mood and anxiety disorders often have poorer weight outcomes 6 months after gastric bypass. ${ }^{8}$ According to the review conducted by Yen et al. (2014), weight loss improves cognitive function and depressive symptoms, but it does not improve anxiety. ${ }^{5}$ The BAI scale contains some physical symptoms which are also symptoms of dumping. Thus, one possible reason of the association between lower BAI score and weight regain is that those reporting fewer symptoms such as dizziness, sweating, and pounding heart might also have less physical response when eating food that triggers dumping. ${ }^{29}$

Different from what was observed in the present study, some studies have identified risky alcohol consumption as an important problem in younger patients undergoing bariatric surgery. A prospective cohort study of 2458 adults, with a mean age of 47 years, undergoing bariatric surgery in several medical centers in the United States found that the prevalence of alcohol use disorder was higher in the second postoperative year than in the year prior to surgery or in the first postoperative year. Also, alcohol use disorder was associated with male sex, younger age, undergoing Roux-en-Y gastric bypass, and numerous preoperative variables (smoking, regular alcohol consumption, alcohol abuse, recreational drug use, and lower interpersonal support). ${ }^{18}$ The study also suggested that worse mental health and postoperative treatment of psychiatric or emotional problems were significantly associated with alcohol use disorder. ${ }^{18}$ Older age, in fact, appears to be associated with a decreased likelihood of alcohol abuse. ${ }^{30}$
Although we do not have preoperative data for comparison, we can assume that the older adults evaluated in our study did not significantly increase their alcohol consumption, since other Brazilian studies point to a rate of risky alcohol use of about 5.0\%. ${ }^{31}$ Excessive alcohol consumption is related to tobacco and illicit drug use, in addition to contributing to the development of psychosocial disorders, such as depression, thoughts of self-destruction, and behavioral disorders.

In the present study, no older adult had presence of binge eating behavior. There may be some explanations for this finding. First, the older adults who had risky alcohol consumption postoperatively may have substituted one addiction (food) for another addiction (alcohol). There are also data showing an altered absorption of alcohol post-surgery that could be an alternative explanation for the increased risk of alcohol abuse post-surgery. ${ }^{32}$ Besides, the lack of a more objective assessment was a limitation. Second, some older adults may have omitted information about binge eating because they felt embarrassed to assume the behavior or even due to a lack of perception of this compulsive behavior. Last, binge eating may have been under-reported because post-bariatric patients cannot eat objectively large amounts of food.

This study has some limitations. First, its cross-sectional design does not allow the assessment of preoperative depression and anxiety symptoms, risky alcohol consumption, or binge eating, thus precluding a cause-and-effect analysis. Second, the small sample size, the fact that all procedures were performed by the same surgeon and that only one type of bariatric surgical procedure (Roux-en-Y) was included prevent the generalization of the results to other services and countries. The measures for depression and anxiety used in this study only assess symptoms in the past two weeks or past month, thus not really examine the general presence of psychopathology in the six years after surgery - only current/very recent psychopathology. Finally, many eligible patients refused to participate, and this may have influenced the results by underestimating the prevalence of the comorbidities under study. Peterhänsel et al. reported that patients who have regained weight are often embarrassed to keep attending medical follow-up visits, did not have adequate follow-up and do not trust the surgeon. ${ }^{33}$ However, we believe that some strengths of the study should be noted, such as the mean patient age (65.80 years), the length of time since surgery (mean of six years), and the scales and questionnaires used as measurement tools, which were suitable for the disorders under study.

The results of this study indicate that, after a mean of six years of bariatric surgery, older adults are psychologically well-adjusted, with a low prevalence of depressive symptoms, anxiety symptoms, and risky alcohol consumption, without 
binge eating behavior, and without manifestations of active psychiatric disorders or significant symptoms. With the increased number of bariatric procedures performed in older adults, further research is warranted to address aspects of mental health and quality of life in this age group, preferably longitudinal, long-term follow-up studies. It remains unknown whether clinical variables, such as vitamin deficits, may at some point after surgery negatively impact the mental health of these individuals.

\section{CONFLICT OF INTERESTS}

The authors declare no conflict of interest.

\section{FUNDING}

None.

\section{AUTHORS' CONTRIBUTION}

EFC: Conceptualization, Data curation, Formal analysis, Writing - original draft, Writing - review \& editing. MCPF: Conceptualization, Data curation, Formal analysis, Writing - original draft, Writing - review \& editing. JBC: Conceptualization, Data curation, Formal analysis, Writing - review \& editing. OTN: Conceptualization, Writing review \& editing. SLMA: Conceptualization, Writing review \& editing.

\section{REFERENCES}

1. Hoyos DTN, Salazar MÁM. La cirugía bariátrica: una vivencia espinosa pero satisfactoria. Enferm glob [Internet] 2016 [cited on Jul. 29, 2021];15(43):212-27. Available from: http://scielo.isciii.es/scielo. php?script=sci_arttext\&pid=S1695-61412016000300009\&lng=es

2. Dorman RB, Abraham AA, Al-Refaie WB, Parsons HM, Ikramuddin S, Habermann EB. Bariatric surgery outcomes in the elderly: an ACS NSQIP study. J Gastrointest Surg. 2012;16(1):35-44. https:// doi.org/10.1007/s11605-011-1749-6

3. Quirante FP, Montorfano L, Rammohan R, Dhanabalsamy N, Lee A, Szomstein $\mathrm{S}$, et al. Is bariatric surgery safe in the elderly population? Surg Endosc. 2017;31(4):1538-43. https://doi.org/10.1007/s00464016-5050-3

4. Sarwer DB, Wadden TA, Fabricatore AN. Psychosocial and behavioral aspects of bariatric surgery. Obes Res. 2005;13(4):639-48. https:// doi.org/10.1038/oby.2005.71

5. Yen YC, Huang CK, Tai CM. Psychiatric aspects of bariatric surgery. Curr Opin Psychiatry. 2014;27(5):374-9. https://doi.org/10.1097/ YCO.0000000000000085

6. Cunha JB, Fialho MCP, Arruda SLM, Nóbrega OT, Camargos EF. Bariatric surgery as a safe and effective intervention for control of comorbidities in elderly. Geriatr Gerontol Aging. 2020;14(3):207-12. https://doi.org/10.5327/Z2447-212320202000037

7. Cunha JB, Fialho MCMP, Arruda SLM, Nóbrega OT, Camargos EF. Clinical and metabolic improvement after bariatric surgery in older adults: a 6-year follow-up. J Nutr Health Aging. 2020;24(8):865-9. https://doi.org/10.1007/s12603-020-1406-4

8. Kalarchian MA, Marcus MD, Levine MD, Soulakova JN, Courcoulas AP, Wisinski MS. Relationship of psychiatric disorders to 6-month outcomes after gastric bypass. Surg Obes Relat Dis. 2008;4(4):544-9. https://doi.org/10.1016/j.soard.2008.03.003

9. Dawes AJ, Maggard-Gibbons M, Maher AR, Booth MJ, Miake-Lye I, Beroes JM, et al. Mental health conditions among patients seeking and undergoing bariatric surgery: a meta-analysis. JAMA. 2016;315(2):150-63. https://doi.org/10.1001/jama.2015.18118

10. Zwaan M, Enderle J, Wagner S, Mühlhans B, Ditzen B, Gefeller O, et al. Anxiety and depression in bariatric surgery patients: a prospective, follow-up study using structured clinical interviews. J Affect Disord. 2011;133(1-2):61-8. https://doi.org/10.1016/j.jad.2011.03.025

11. Karlsson J, Taft C, Ryden A, Sjöström L, Sullivan M. Ten-year trends in health-related quality of life after surgical and conventional treatment for severe obesity: the SOS intervention study. Int J Obes (Lond). 2007;31(8):1248-61. https://doi.org/10.1038/sj.ijo.0803573

12. Legenbauer T, Zwaan M, Benecke A, Mühlhans B, Petrak F, Herpertz S. Depression and anxiety: their predictive function for weight loss in obese individuals. Obes Facts. 2009;2(4):227-34. https://doi. org/10.1159/000226278
13. Legenbauer T, Vocks S, Betz S, Puigcerver MJB, Benecke A, Troje $\mathrm{NF}$, et al. Differences in the nature of body image disturbances between female obese individuals with versus without a comorbid binge eating disorder: an exploratory study including static and dynamic aspects of body image. Behav Modif. 2011;35(2):162-86. https://doi.org/10.1177/0145445510393478

14. Semanscin-Doerr DA, Windover A, Ashton K, Heinberg LJ. Mood disorders in laparoscopic sleeve gastrectomy patients: does it affect early weight loss? Surg Obes Relat Dis. 2010;6(2):191-6. https:// doi.org/10.1016/j.soard.2009.11.017

15. Ertelt TW, Mitchell JE, Lancaster K, Crosby RD, Steffen KJ, Marino JM. Alcohol abuse and dependence before and after bariatric surgery: a review of the literature and report of a new data set. Surg Obes Relat Dis. 2008;4(5):647-50. https://doi.org/10.1016/j. soard.2008.01.004

16. Sjöström L, Narbro K, Sjöström CD, Karason K, Larsson B, Wedel $\mathrm{H}$, et al. Effects of bariatric surgery on mortality in Swedish obese subjects. N Engl J Med. 2007;357(8):741-52. https://doi.org/10.1056/ NEJMoa066254

17. Woodard GA, Downey J, Hernandez-Boussard T, Morton JM. Impaired alcohol metabolism after gastric bypass surgery: a case-crossover trial. J Am Coll Surg. 201 1;212(2):209-14. https://doi.org/10.1016/j. jamcollsurg.2010.09.020

18. King WC, Chen JY, Mitchell JE, Kalarchian MA, Steffen KJ, Engel SG, et al. Prevalence of alcohol use disorders before and after bariatric surgery. JAMA. 2012;307(23):2516-25. https://doi.org/10.1001/ jama.2012.6147

19. Svensson PA, Anveden Å, Romeo S, Peltonen M, Ahlin S, Burza MA, et al. Alcohol consumption and alcohol problems after bariatric surgery in the Swedish obese subjects study. Obesity (Silver Spring). 2013;21(12):2444-51. https://doi.org/10.1002/ oby.20397

20. Boas MAV. Estatuto do idoso comentado. São Paulo: Editora Forense; 2005.

21. Cunha JA. Manual da versão em português das Escalas Beck. São Paulo: Casa do psicólogo. 2001; p. 256.

22. Gomes-Oliveira MH, Gorenstein C, Lotufo Neto F, Andrade LH, Wang YP. Validação da versão brasileira em português do inventário de depressão de Beck-II numa amostra da comunidade. Braz J Psychiatry. 2012;34(4):389-94. https://doi.org/10.1016/j.rbp.2012.03.005

23. Santos WS, Gouveia VV, Fernandes DP, Souza SSB, Grangeiro ASM. Alcohol Use Disorder Identification Test (AUDIT): explorando seus parâmetros psicométricos. J Bras Psiquiatr. 2012;61(3):117-23. https://doi.org/10.1590/S0047-20852012000300001 
24. Gormally J, Black S, Daston S, Rardin D. The assessment of binge eating severity among obese persons. Addict Behav. 1982;7(1):4755. https://doi.org/10.1016/0306-4603(82)90024-7

25. Freitas S, Lopes CS, Coutinho W, Appolinario JC. Tradução e adaptação para o português da Escala de Compulsão Alimentar Periódica. Braz J Psychiatry. 2001;23(4):215-20. https://doi.org/10.1590/ S1516-44462001000400008

26. Sjöström L, Lindroos AK, Peltonen M, Torgerson J, Bouchard C, Carlsson B, et al. Lifestyle, diabetes, and cardiovascular risk factors 10 years after bariatric surgery. N EngI J Med. 2004;351(26):268393. https://doi.org/10.1056/NEJMoa035622

27. Nijamkin MP, Campa A, Nijamkin SS, Sosa J. Comprehensive behavioral-motivational nutrition education improves depressive symptoms following bariatric surgery: a randomized, controlled trial of obese Hispanic Americans. J Nutr Educ Behav. 2013;45(6):620-6. https://doi.org/10.1016/j.jneb.2013.04.264

28. Henrickson HC, Ashton KR, Windover AK, Heinberg LJ. Psychological considerations for bariatric surgery among older adults. Obes Surg. 2009;19(2):211-6. https://doi.org/10.1007/s11695-0089768-4
29. Chaves YS, Destefani AC. Pathophysiology, diagnosis and treatmentof dumping syndrome and its relation to bariatric surgery. Arg Bras Cir Dig. 2016;29(Suppl 1):116-9. https://doi.org/10.1590/01026720201600510028

30. Lent MR, Hayes SM, Wood GC, Napolitano MA, Argyropoulos G, Gerhard GS, et al. Smoking and alcohol use in gastric bypass patients. Eat Behav. 2013;14(4):460-3. https://doi.org/10.1016/j. eatbeh.2013.08.008

31. Barbosa MB, Pereira CV, Cruz DT, Leite ICG. Prevalence and factors associated with alcohol and tobacco use among non-institutionalized elderly persons. Rev Bras Geriatr Gerontol. 2018;21(2):123-33. https://doi.org/10.1590/1981-22562018021.170185

32. Steffen KJ, Engel SG, Wonderlich JA, Pollert GA, Sondag C. Alcohol and other addictive disorders following bariatric surgery: prevalence, risk factors and possible etiologies. Eur Eat Disord Rev. 2015;23(6):44250. https://doi.org/10.1002/erv.2399

33. Peterhänsel C, Petroff D, Klinitzke G, Kersting A, Wagner B Risk of completed suicide after bariatric surgery: a systematic review. Obes Rev. 2013;14(5):369-82. https://doi.org/10.1111/ obr.12014 